\title{
ACCIDENTS AMONG CHILDREN UNDER TWO YEARS OF AGE IN GREAT BRITAIN
}

\author{
[SOME FINDINGS OF A NATIONAL QUESTIONNAIRE INQUIRY \\ CaRried out by a Joint Committee of the Royal College \\ of Obstetricians and Gynaecologists, the Population \\ Investigation Committee and the Institute of Child \\ Health (UNIVERSity OF LoNdon) WITH THE AID OF A GRANT \\ FROM the Nuffield Foundation]
}

BY G. ROWNTREE

\section{INTRODUCTION}

The object of this paper is to discuss the incidence and cause of accidents among young children. The material on which the study was based was collected in the course of a national questionnaire inquiry into the health and development of children born in Great Britain in the week 3-9 March 1946. Full information was obtained in this inquiry from $91 \%$ of the mothers of those children who had survived the first 2 years of life. It is hoped that similar studies of the same sample will be undertaken at regular intervals as the children grow older so that a complete picture can be obtained of the incidence and effects of accidents throughout childhood.

Few studies have been made of the incidence of accidents among the total population of young children. The Registrar-General's figures cover fatal accidents only, and the various national sample surveys do not deal with the problem fully. For example, the American National Health Survey among the urban population in 1935-36 omitted accidents which caused less than 7 days' disablement (Britten, Klebba \& Hailman, 1940), and the current monthly surveys of sickness in Britain, carried out by the Social Survey for the Ministry of Health, do not include the child population (Stocks, 1949).

Most of the previous studies of the social aspects of accidents have been confined to investigating the home environment of children treated for injuries in the departments of individual hospitals (Donald, 1930; Dunbar, 1934). These studies have shown that in spite of the general decrease in serious and fatal accidents (fatal accidental burns among the civilian population in England and Wales occurred at the rate of 30 per million in 1938 and only 20 per million in 1947), a relatively high proportion of certain types of accident continue to occur among young children. For example, $11.7 \%$ of all deaths from accidental burns and scalds in England and Wales in 1947 occurred among children under 2 years of age, although this age group was only $3.7 \%$ of the total population. A very high proportion of accident cases admitted to individual hospitals were children. For 
instance, Brown, Lewis-Faning \& Whitter (1945) found that $25 \%$ of the burns cases admitted to the Burns Unit of the Glasgow Royal Infirmary over a period of 14 months in 1942-3 were under 3 years of age; Colebrook \& Colebrook (1949) calculated $53 \%$ of the burns and scalds treated at the Medical Research Council Burns Unit, Birmingham Accident Hospital, happened to children under 5 years; and Wilkinson (1944) showed that $88 \%$ of all the burns cases in the accident wards of the Edinburgh Royal Hospital for Sick Children between 1938-42 were under 5 years, $70 \%$ under 3 years.

Young children seem to be exposed to particularly serious hazards, especially burns, and it is therefore important to discover what the national incidence of child accidents is, together with the chief causes. With these objects in mind, the Joint Committee included in its general investigation of infant health and development a study of the accidental injuries sustained by the national sample of children under 2 years of age.

\section{METHODS}

Two years before the present inquiry the Joint Committee had undertaken a national questionnaire survey of the social aspects of child-bearing, taking for the sample all mothers who had been confined in the week 3-9 March 1946. A total of 424 of the 458 health authorities then in existence in England, Wales and Scotland agreed to co-operate in this maternity survey by allowing their health visitors to obtain answers to the Joint Committee's questionnaire from the mothers in the sample. The authorities which did not participate were chiefly small municipal boroughs and urban districts. The response from the mothers was remarkably good, completed questionnaires being returned for 13,687 or $90.5 \%$ of all those living in the areas of co-operating authorities. A detailed account of the findings and methods used in the maternity survey will be found in Maternity in Great Britain (1948).

The success of the maternity survey encouraged the Joint Committee to embark in 1948 on the present inquiry, the follow-up survey, which was designed to investigate the health and development of the children whose births had been studied in 1946. The authorities co-operating in 1946 were again approached and all but two (which were small municipal boroughs) agreed to participate again. Their health visitors approached the mothers for the second time with the follow-up questionnaire in March 1948 on or near the date of the sample children's second birthdays.

In order to reduce the amount of work required from the health visitors, the Joint Committee decided to cut down the number of interviews to be attempted in the follow-up survey. Twins, stillbirths and illegitimate children were excluded. Each family included in the maternity survey sample had been allocated to one of five broad social groups according to details collected in the survey on the father's occupation. Only one in four mothers found in the maternity survey to belong to the very large social group of manual workers' wives, and a similar proportion of mothers in the 'other occupations' group (chiefly wives of farmers and small shopkeepers), were selected for this second interview, together with all 
the wives of professional and salaried, black-coated and agricultural workers. In analysing the results corrections were made for sampling by multiplying figures for the manual worker and 'other occupations' groups by 4 .

The health visitors were successful in tracing and interviewing 4848 or $90 \%$ of the mothers in this sample; in $\mathbf{1 4 5}$ of these families the survey children born in March 1946 had died before their second birthdays, leaving 4703 alive at the date of interview in 1948. Death of the survey child or emigration of the family were the chief reasons for failure to interview, and as Table 1 shows, there were only

Table 1. Comparison of completed and attempted interviews

(a) Social class

Interviews with wives of

\begin{tabular}{|c|c|c|c|c|c|c|}
\hline & $\begin{array}{c}\text { Professional } \\
\text { and salaried } \\
\text { workers } \\
(\%)\end{array}$ & $\begin{array}{c}\text { Black- } \\
\text { coated wage } \\
\text { earners } \\
(\%)\end{array}$ & $\begin{array}{c}\text { Manual } \\
\text { workers } \\
(\%)\end{array}$ & $\begin{array}{l}\text { Agricultural } \\
\text { workers } \\
(\%)\end{array}$ & $\begin{array}{c}\text { Men in } \\
\text { other } \\
\text { occupations } \\
(\%)\end{array}$ & Total \\
\hline $\begin{array}{l}\text { Completed } \\
\text { interviews }\end{array}$ & $18 \cdot 9$ & $25 \cdot 6$ & $41 \cdot 1$ & 10.5 & 3.9 & $\begin{array}{r}100 \cdot 0 \\
(4848)\end{array}$ \\
\hline $\begin{array}{l}\text { All attempted } \\
\text { interviews }\end{array}$ & $20 \cdot 0$ & $25 \cdot 7$ & $40 \cdot 1$ & $10 \cdot 4$ & $3 \cdot 8$ & $\begin{array}{l}100 \cdot 0 \\
(5380)\end{array}$ \\
\hline
\end{tabular}

(b) Birth order

Interviews with women of the following parities

\begin{tabular}{|c|c|c|c|c|}
\hline $\begin{array}{l}\text { First } \\
(\%)\end{array}$ & $\begin{array}{l}\text { Second } \\
\text { and third } \\
(\%)\end{array}$ & $\begin{array}{c}\text { Fourth } \\
\text { and higher } \\
(\%)\end{array}$ & $\begin{array}{c}\text { Unknown } \\
(\%)\end{array}$ & Total \\
\hline $39 \cdot 0$ & $46 \cdot 1$ & $14 \cdot 7$ & $0 \cdot 2$ & $\begin{array}{r}100 \cdot 0 \\
(4848)\end{array}$ \\
\hline $40 \cdot 2$ & $45 \cdot 5$ & $14 \cdot 2$ & 0.2 & $\begin{array}{c}100 \cdot 1 \\
(5380)\end{array}$ \\
\hline
\end{tabular}

(c) Age of mother

Interviews with mothers aged

\begin{tabular}{|c|c|c|c|c|c|}
\hline & $\begin{array}{c}\text { Up to } \\
24 \text { years } \\
(\%)\end{array}$ & $\begin{array}{c}25-34 \text { years } \\
(\%)\end{array}$ & $\begin{array}{c}\text { Over } \\
34 \text { years } \\
\text { (\%) }\end{array}$ & $\begin{array}{l}\text { Unknown } \\
(\%)\end{array}$ & Total \\
\hline $\begin{array}{l}\text { Completed } \\
\text { interviews }\end{array}$ & $21 \cdot 4$ & $56 \cdot 6$ & $21 \cdot 7$ & $0 \cdot 3$ & $\begin{array}{l}100 \cdot 0 \\
(4848)\end{array}$ \\
\hline $\begin{array}{l}\text { All attempted } \\
\text { interviews }\end{array}$ & $22 \cdot 4$ & $56 \cdot 4$ & $20 \cdot 9$ & 0.4 & $\begin{array}{c}100 \cdot 1 \\
(5380)\end{array}$ \\
\hline
\end{tabular}

(d) Country

$\begin{array}{cccc}\overbrace{\begin{array}{c}\text { England } \\ \text { and Wales } \\ (\%)\end{array}}^{\text {Interviews in }} & \begin{array}{c}\text { Scotland } \\ (\%)\end{array} & \text { Total } \\ \begin{array}{c}\text { Completed } \\ \text { interviews }\end{array} & 87.5 & 12.5 & 100 \cdot 0 \\ \begin{array}{c}\text { All attempted } \\ \text { interviews }\end{array} & 87.6 & 12 \cdot 3 & \mathbf{( 4 8 4 8 )} \\ & & & \mathbf{9 9 . 9} \\ & & & \mathbf{5 3 8 0 )}\end{array}$


minor differences between the completed and all-attempted interviews in respect of social class, birth order, age of mother, and region.

The completed interviews appeared to be an unbiased sample (see Douglas \& Rowntree, 1949). The incidence of accidents in this sample should therefore be a reliable indication of the national incidence among young children.

\section{DATA AVAILABLE ON ACCIDENTS IN THE FOLLOW-UP SURVEY}

At the follow-up interview each mother was asked whether her 2-year-old child had ever had either a burn or scald, a bad cut or bruise, or broken a bone. If any of those accidents had occurred she was asked to say how many months old the child was when it had happened, what part of the body had been injured and who had treated the injury. The health visitors were instructed to inquire how the accidents had occurred, and to enter the causes briefly on the questionnaires. This information was obtained from 4683 mothers of survey children; twenty women who were otherwise successfully interviewed, failed to give details on accidents.

In the national Survey of Sickness it has been found that some people fail to remember ailments and injuries even over as short a period as 2 months (Stocks, 1949). In designing the present inquiry it was realized that, however great the mothers' care and interest in their children's health might be, the memory factor might affect the reliability of the survey information, especially as the data on accidents occurring during a 2-year period was collected only at the end of that period. Though mothers would be likely to remember serious accidents involving hospital and medical treatment, their ability to recall minor injuries, not requiring professional care, probably varied greatly. Minor accidents appear to have been remembered and recorded more often when they occurred shortly before the date of interview than when they happened earlier; thus, $37 \%$ of these slight injuries were recorded as having occurred when the children were 21-24 months old, and only $24.5 \%$ were reported for the ages 17-20 months. On the other hand, the more serious accidents which required medical treatment occurred most frequently, according to the survey data, when the children were 17-20 months old: $28.9 \%$ occurred at this period and $23 \cdot 2 \%$ at $21-24$ months. Thus it is probable that the more serious injuries were on the whole remembered well, while the slight accidents at an early age were not always entered on the questionnaire.

Unfortunately the accuracy of the data on age and type of treatment could not be checked against independent records, since the addresses of hospitals and doctors who gave treatment were not recorded at the interview. However, details on other subjects covered by the questionnaire seem to have been reported with remarkable accuracy, and it appears that the mothers have remembered the details of their children's health and development, including injuries, remarkably well. Comparisons between the survey data and local records in six welfare authorities showed close agreement: 118 mothers in these areas said at the interview that their children had been immunized, and this was confirmed in 112 cases by the local records; further, 110 of these mothers said that they had taken their children to infant welfare centres, and 104 of these were listed in the centre registers as having done so. 
So far as the ages at accidents were concerned there was a tendency to say that injuries had occurred in birthday and other key months, such as the 12th and 18th, 'and allowance had to be made for this kind of 'bunching' when analysing the material. Complete accuracy on every detail cannot be claimed in an extensive national investigation of this kind, but the survey data appeared to be sufficiently reliable for an estimate of the national incidence of accidents to be made.

\section{INCIDENCE OF ACCIDENTS}

The incidence of accidents among children under 2 years could only be calculated on the basis of the total number of children surviving to the second birthday, and therefore each exposed to the risk of accidents for the full period of 24 months. The survey data on the accidents occurring to children who died before they were 2 years old was in any case incomplete since $30 \%$ of the mothers of these dead children were not interviewed. Information was obtained, however, on the causes of all the 207 deaths of sample children, whether or not their mothers were interviewed; accidents accounted for only two of these deaths, which were both due to asphyxia at an early age, one being caused by accidental smothering in a pillow, the other by overlying.

A total of 348 surviving children of 2 years of age had had either a burn, a scald, or bad cut or bruise or a fracture which had been treated by a doctor or in a hospital department. After corrections are made for sampling, this total represents an accident rate of $79 \cdot 6$ per 1000 children. Another 262 children (57.5 per 1000) were reported to have had slight injuries for which medical treatment was not obtained. As mentioned above, the possibility of forgetting slight accidents seemed considerable, and for this reason the incidence of minor injuries given here is probably a less reliable estimate than the figures given for treated accidents. Consequently, the following discussion is devoted chiefly to an analysis of the latter.

We can be certain that the treated injuries included all the most serious accidents. Of course, medical or hospital treatment is not an exact measure of severity, since the source of treatment of relatively slight injuries may depend on access to medical care and on the varying habits of mothers in consulting doctors and outpatients' departments. It must be remembered that the survey was undertaken before the National Health Service Act came into force. However, for serious injuries few families in Britain were completely isolated from medical facilities in 1946-8, and the proportion of children with treated injuries, given above, provides in all probability a fair estimate of the incidence of more serious accidents among children under 2 years.

The Registrar-General's data on fatal accidents show a higher rate for boys than for girls, even in early years. Thus in 1947, the death-rate for accidents was 1.74 per 1000 for boys under 1 year of age, and 1.33 for girls. Although a small sex difference was found in the incidence of the more serious, but non-fatal accidents occurring to survey children under 2 years of age, this difference was not statistically significant. It is probable, however, that further investigation as the 
survey children grow older will show more marked differences between boys and girls.

Almost all of the 348 children had only one serious treated injury before their second birthdays. There were, however, eight children who had been seriously injured more than once, sustaining burns as well as either a fracture or a severe cut. It was, of course, impossible to make a study of accident-proneness since the total number of children having more than one accident was so small; only seventeen children had more than one accident, either slight or severe.

The types of injuries sustained by survey children are shown in Table 2 according to the source of treatment. A child who has been injured twice, sustaining, for example, both a burn and a cut, is counted twice in this table, once in the burns column and again in the column for cuts and bruises. The total incidence of injuries which can be calculated for this table is therefore slightly higher than the rates given above for children injured.

\section{Table 2. Incidence of accidents by source of treatment}

Injuries per 1000 children

Source of treatment

Hospital

Accident or other ward

Out-patients' department

General practitioner

All sources of treatment

Not treated

$\begin{array}{ccc}\begin{array}{c}\text { Burns } \\ \text { and scalds }\end{array} & \begin{array}{c}\text { Bad cuts } \\ \text { and bruises }\end{array} & \text { Fractures } \\ & & \\ 5 \cdot 1 & 0 \cdot 2 & 1 \cdot 2 \\ 7 \cdot 6 & 13 \cdot 0 & 4 \cdot 9 \\ 24 \cdot 4 & 23 \cdot 5 & 1 \cdot 4 \\ 37 \cdot 1 & 36 \cdot 7 & 7 \cdot 5 \\ 35.5 & & \\ & 26.3 & -\end{array}$

* Rates were calculated from data given in Table 3 after correcting for sampling.

It is at once clear that general practitioners provided treatment for burns and for cuts very much more often than hospitals. Bad cuts and bruises, which were almost as frequent as burns and scalds, were also treated by doctors to the same extent. Cases of burns and scalds were more frequently admitted to accident wards, cuts and bruises being treated chiefly in out-patients' departments. All the fractures recorded received professional care, chiefly at out-patients' departments.

The rates given in the table can be used for calculating very approximately the total annual incidence of these serious accidents among young children. It must, of course, be remembered that the table refers only to the group of children reaching their second birthdays in March 1948, and not to all children under 2 years of age at that date. This difficulty can to some extent be overcome by the application of a life-table technique to the survey data. It is, however, impossible to eliminate the effect of seasonal differences on the incidence of some types of accident, such as burns from domestic fires: the survey children were all beginning to walk in the spring and summer of 1947, and the risk of their falling into or against live domestic fires was likely to be less than for children beginning to walk in the winter months. The annual total of burns, as calculated from the survey data, is therefore likely to be an underestimate of the actual total. 


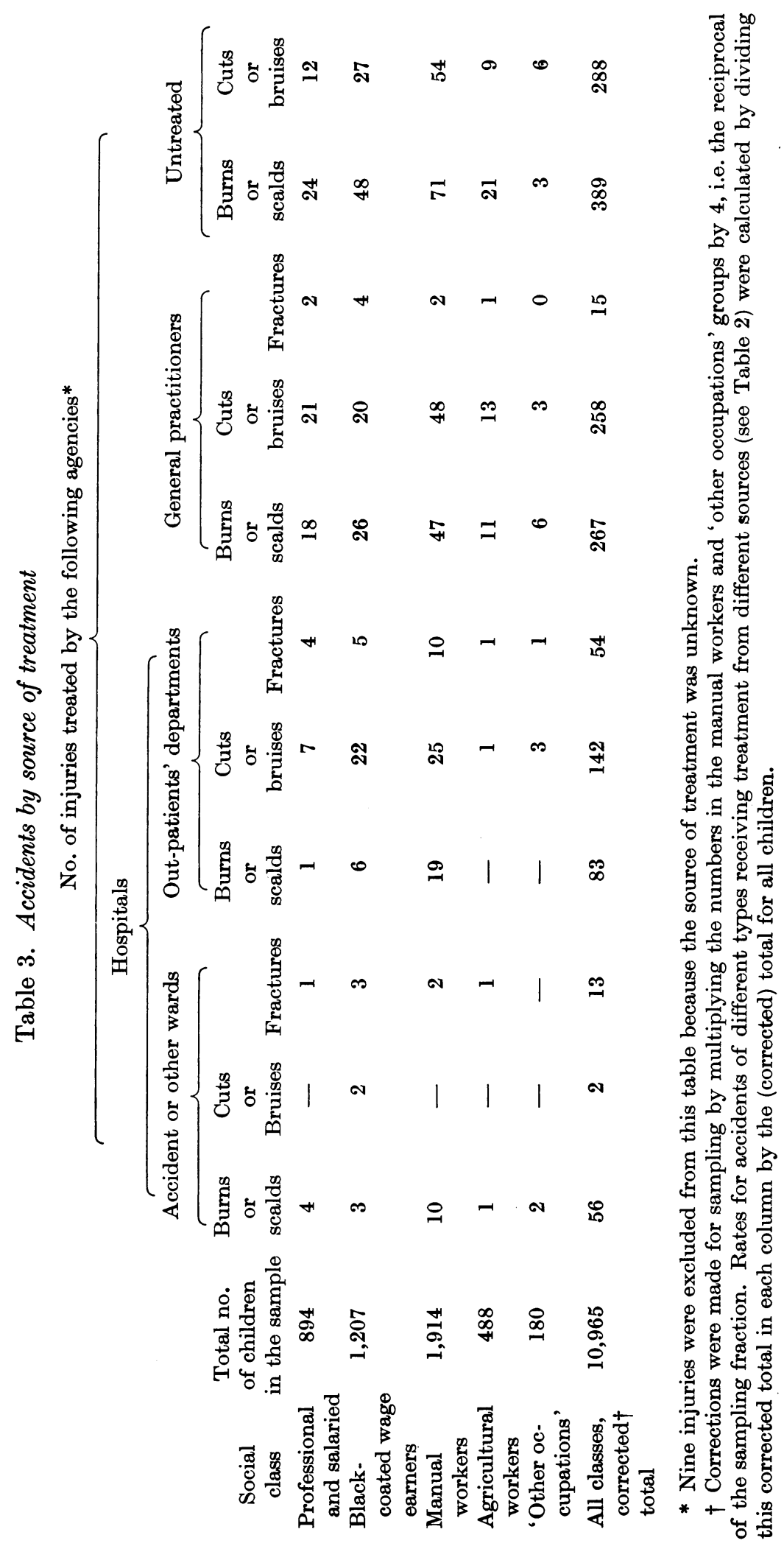


Bearing these reservations in mind, the survey data appear to suggest that during one year doctors and hospital departments treated about 15,000 severe burns or scalds, 16,000 bad cuts or bruises, and 4000 fractures among an estimated total of $1,740,000$ children under 2 years of age in Britain in 1947. This was before the National Health Service Act came into force. Over 35,000 injuries to very young children must have been treated annually, 3000 in accident wards, 11,000 in outpatients' departments and 21,000 by general practitioners, involving an enormous amount of work for hospital and medical services. Moreover, some of these accidents, besides causing at the time both pain to the children and anxiety to the parents, must have resulted in permanent disability or disfigurement. It is hoped that the extent of these disabilities will be studied in future investigations.

\section{CAUSES OF ACCIDENTS TO CHILDREN UNDER 2 YEARS OF AGE}

Most of the injuries to children under 2 years occurred in the home. Among the treated injuries there were only three resulting from motor accidents, and four others which took place away from the children's usual surroundings, i.e. the house or the garden. The risks to which the children were exposed were therefore chiefly associated with the home environment. Although home conditions are to a large extent determined by family income and social class, the total number of accidents was too small for the incidence of accidents in the different social classes to be compared.

In the American National Health Survey of 1935-6 (Britten \& Altman, 1941), it was found that among children under 5 years of age (and also in other age groups) the incidence of accidents which disabled for more than 1 week was higher among occupants of poor dilapidated dwellings (as measured by the low rents paid) than among those living in dwellings of better quality, i.e. high-rented accommodation or high-valued owner-occupied property. The present follow-up survey data were analysed in order to establish whether a similar association existed between poor housing conditions and high accident rates among children under 2 years of age in Great Britain.

During the interviews information was obtained from each household on the number of persons per room, the type and ownership of the dwelling, the kitchen and washing facilities and the availability of a yard or garden. In addition, the health visitors had been asked to make an assessment of the general state and structure of the dwelling as either 'good', 'fair' or 'poor'. The households, in which serious medically treated accidents had occurred to survey children were analysed according to these various aspects of home environment. A similar analysis was made for an equal number of control households in which accidents to young children had not occurred. In order to eliminate any effects which size of family, social class or regional variations might have on housing conditions, the controls were selected by matching each of the children having an accident against a child who had not been injured at all, but came from the same broad social group, from a family of similar structure and living in the same area, or a neighbouring one of similar administrative status. It was possible to find 215 pairs who matched in these respects. 
When comparisons were made between the accident and control groups, it was found that the two groups hardly differed at all so far as the various aspects of housing, given above, were concerned. Only in the burns cases and their controls was a significant difference found in the proportion of households assessed by the health visitors as 'fair' or 'poor'. These comprised $15 \cdot 2 \%$ of all the households in which burns had occurred to the survey children, and only $6.2 \%$ of the households where the children had not suffered burns $\left(X^{2}=4 \cdot 4, n=1, P=0 \cdot 05-0 \cdot 02\right)$. But significant differences were not found in this assessment among the cases of fractures or bad cuts and their matched pairs. In other respects the housing conditions of the two groups were similar.

This analysis of the survey data, therefore, leads us to the conclusion that housing conditions, as measured by such items as crowding, domestic facilities and the health visitors' assessments of the state of the dwelling were not the chief factors associated with a high incidence of accidents among children under 2 years of age.

This conclusion at first appears surprising: a general knowledge of the hazards of obsolete dwellings and the evidence from the American National Health Survey had suggested that accidents would be more frequent in poor and over-crowded home circumstances than in comfortable, less crowded dwellings in good repair. However, the fact that children under 2 years of age were equally exposed to risks of accidents whatever their home conditions may possibly be explained by the stages of development through which they were passing in the early years of life. While still immobile and sleeping for most of the day, the risks of injury were slight, being largely limited to the possibility of rolling off a bed or out of the cot or being burnt while lying on the hearth rug by a live coal spurting from the fire. But when the children were beginning to sit up, to grab objects within reach and especially when they were beginning to walk, they were exposed to many more risks, whatever kind of home they were living in. Gesell \& Ilg (1943) have described children of 15 months as 'ceaselessly active, with brief bursts of locomotion, starting, stopping, starting again, climbing and clambering'. In these activities they might trip against or fall off furniture, and tumble down steps or into the hearth. Growing more curious as well as more mobile they would begin to prod and touch strange objects, and might put their fingers in hot food, cut themselves on knives or broken glass or touch live coals or naked flames.

The chief causes of the serious medically treated accidents in the present sample are shown in Table 4, together with the age or stage of development at which they occurred. The considerable variety of causes and the small numbers involved have made some grouping necessary in this table. Scalds from boiling kettles and hot cups of tea were combined, and so were burns caused by various items of domestio equipment, cooking stoves, coppers, boilers, cooking utensils, hot food and irons. Electric and gas heaters as well as open coal fires were included under the heading 'domestic fires'. The burns from other causes included those due to inadequately protected hot-water bottles, lighted cigarettes, and playing with boxes of matches. Various causes of cuts and fractures were also combined: falls were grouped under two headings, first those from cots, high chairs and beds which could mainly 


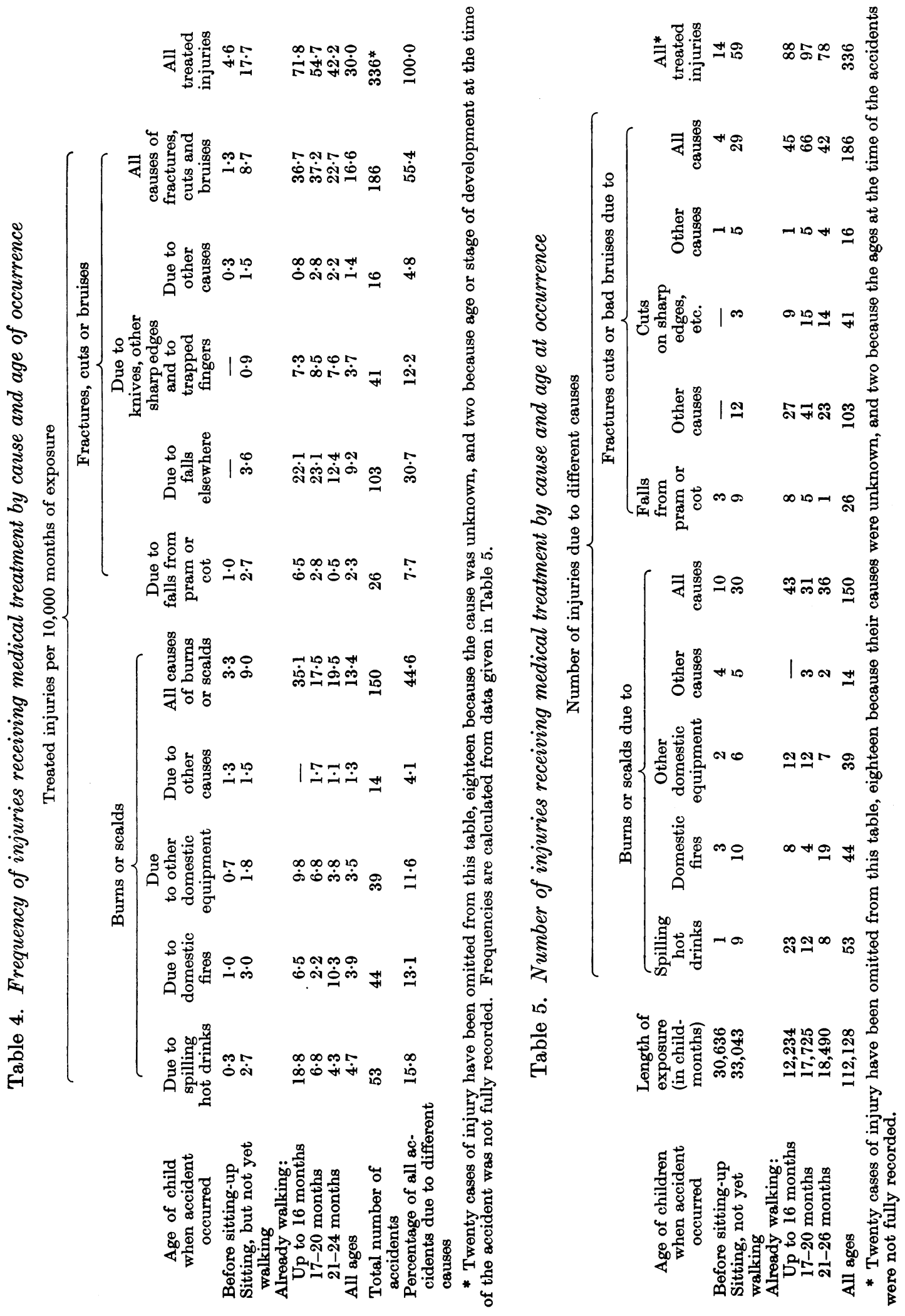


be attributed to lack of supervision at the time of the accident, and secondly those which occurred when the child was moving about, i.e. falls against and off furniture, and down steps. Cuts caused by sharp instruments and by broken glass were combined with cases where children's fingers were trapped, either in doors or in household equipment, such as the mangle. Other causes of cuts and fractures included falls from heights (one child fell out of a window, another fell down a $30 \mathrm{ft}$. pit in a runaway pram), car accidents (in one case a child had crawled under a stationary vehicle); and bites by dogs and by a tame rabbit.

Table 4 shows the number of accidents due to each cause in relation to the total number of months during which each child was exposed to the risk of accident at each stage of development. Thus, at the ages 17-20 months all the 4672 children were exposed to the risk of accident for a total of $4672 \times 4=18,688$ months. The total 4672 was used since ages at starting to walk or full data on accidents were not recorded for 31 children who have therefore been excluded from the calculations. As we wished to include in this age group only those who were already walking, a deduction of 963 months had to be made for those not yet walking, or only walking for a part of the period, making the months of exposure total 17,725 (i.e. 18,688-963). There were 41 falls against furniture or down steps during this period, giving a rate for this type of injury of $23 \cdot 1$ per 10,000 months exposure, i.e. $(41 \times 10,000) / 17,725$.

The total number of accidents in this table is small. Nevertheless, the incidence by cause and age shows a slight significant increase when the children started sitting-up, and a much more marked and significant increase in each type of injury after the children began to walk about. The only exception was in the case of falls from prams or cots where the increase was not significant. As children became steadier on their feet the rates for most accidents showed a decline. Burns from domestic fires were an exception to this rule, probably because of seasonal variations, mentioned above, in the use of fires for space heating. Most of the survey children were beginning to walk in the spring and summer months of 1947 (they were 16 months old in July of that year) when fires were seldom lighted. The period for which the incidence of burns from this cause was highest, i.e. when the children were 21-24 months old, coincided with the coldest winter months, November 1947-March 1948, when domestic fires would be burning all day.

Since so many of the falls occurred when the children were just beginning to walk and when their balance was still poor, it is not surprising to find that the head was the part of the body cut or badly bruised most frequently: $65 \cdot 6 \%$ of all the falls receiving medical treatment were head injuries. Of course, most of the fractures $(70.9 \%$ ) occurred in the arms. The exposed limbs or face were most likely to be burnt or scalded: $51 \%$ of the treated burns or scalds occurred on the arms, $27.1 \%$ on the head or neck, $13.9 \%$ on the legs and only $8.0 \%$ on the trunk which was normally protected by clothing. The slight injuries which did not receive treatment were sited in the different parts of the body with similar frequencies, except that there was a high proportion of slight burns or scalds on the leg $(30.2 \%$ of all untreated burns or scalds) and fewer on the head or neck than among the more serious, treated injuries.

The following are examples of the types of injury occurring at different stages. 
It must be remembered that such accidents as scalds from cups of tea and falls against furniture (examples of which are given for the period when the child is beginning to sit up and to walk), occur fairly frequently right up to the end of the second year when the interviews were carried out.

\section{Before sitting-up}

(1) A second child in a working-class family, owner occupiers of a well-equipped house, was burnt on the face at the age of 3 months by a live coal springing from the open fire on to the hearth rug where she was lying. She was treated by a doctor. (17.68.)

(2) A second child in a well-to-do family was badly bruised and cut on the head at the age of 3 months when his pram was blown over in the garden. A doctor was called in. (184.5.)

Sitting-up but not yet standing

(3) The eighth child of a working class family living in a Glasgow tenement was scalded on the leg when, at the age of 11 months, he pulled a mug of hot tea off the table. He was admitted to hospital as an in-patient. (187.227.)

(4) The first child in a black-coated worker's family sharing a council house was burnt when he was crawling at the age of 9 months and touched a hot bar of the open fire. A doctor treated him. (174.4.)

\section{Soon after beginning to walk}

(5) The third child of a working-class family living in an old terrace house scalded his fingers at the age of 15 months when he put his hand into a pan of hot water to take out an egg. He was treated by a doctor. (144.2.)

(6) A second child in a black-coated worker's family living in a pre-fabricated house fell and cut his arm at the age of 18 months when he was running round with a feeding bottle in his hand. A hospital out-patients' department treated him. (215.18.)

\section{Accidents at a later stage}

(7) The third child in a working-class family burnt his arm when at 20 months he pulled a spoon out of a boiling pudding. He was treated by a doctor. (2.8.)

(8) A second child in a black-coated worker's family living in a flat, fell through the banisters of the staircase at the age of 22 months, and broke his nose. He was treated by a doctor. (187.170.)

(9) A first child of a working-class family living in a council house trapped his hand in the mangle at the age of 23 months. He was treated at an out-patients' department. (102.35.)

(10) A first child in a working-class family living in a council house cut his hand at 20 months with a razor blade which he found lying on the floor. He was treated at an out-patients' department. (45.46.)

Accidents of this description might have occurred in almost any domestic environment. Children in any type of dwelling are liable to bump into furniture, 
fall off chairs, tumble down steps or burn themselves either in the open fire, with kitchen utensils or by grabbing at cups of hot tea. Although children of mothers who had no domestic help were not more likely to suffer injuries than those whose mothers were helped, nevertheless the constant supervision which the unassisted mothers had to give their children must have been a great strain in addition to their usual household duties. Few mothers were able to isolate their active children from the chief domestic hazards by leaving them all the time under separate supervision in rooms away from the household routine. Only about $10 \%$ of all mothers interviewed said that they had full-time help with the housework (these fortunate women included $15.7 \%$ of the wives of professional and salaried workers, and $\mathbf{9 \cdot 4} \%$ of the wives of manual workers), and a further $9 \cdot 3 \%$ were assisted parttime or occasionally (this applied to only $6 \%$ of the manual workers, but to $28.3 \%$ of the well-to-do women). Over four-fifths of the survey mothers had no domestic help at all at the date of interview, and were therefore obliged to do the various household duties, cleaning, cooking, washing and shopping, with the active infant following at their heels during his waking hours. In these circumstances some accidents were inevitable, and many could in fact be attributed entirely to these circumstances. For instance, one mother accidentally trod on her baby's finger when he was playing on the stairs (171.80), and another woman was making up the fire when her child fell on the hot poker (51.23).

Although infants and young children were exposed to many unavoidable risks while learning to walk and playing in the home, some of the hazards could have been removed. Few mothers could be accused of deliberate neglect, since those whose children were injured had as good a record for looking after them as those whose infants had not been hurt. The health visitors were asked to assess the bodily care given to each survey baby and the proportion assessed as 'good' among the 3548 accident cases, $88.0 \%$, was almost identical with that found in the total sample $(88.8 \%$ ). Many women must, however, have been unaware of all the dangers which existed for toddlers in their own homes. Previous studies have shown that open coal fires, unprotected electric elements, teapots, kettles, saucepans, dishes of hot food and, above all, cups of tea, left within reach of inquisitive children are the chief causes of some of the most serious infant injuries. For instance, Wilkinson (1944) had shown that more than $90 \%$ of the cases of burns or scalds admitted to the Edinburgh Royal Hospital for Sick Children between 1938-42 were due to these domestic dangers. In the study of 1000 burns cases admitted to the M.R.C. Burns Unit in Birmingham, Colebrook \& Colebrook (1949) estimated that at least $50 \%$ were preventable. In the present study burns and scalds from hot drinks, fires and other domestic equipment accounted for $40.5 \%$ of all medically treated injuries. It seems probable that many of these could have been avoided if parents had been more fully instructed to take simple precautions and housing design modified with this end in view.

Many accidents were due to open fires: children touched or fell against the grate, or else the clothes caught alight. Hardly any of the materials used for children's clothing are fireproofed, although this is a comparatively inexpensive process (Colebrook \& Colebrook, 1949). 
The clause in the Children's Act (1908) which penalizes parents whose young children have been badly burnt through the failure to protect open fires is, as the Colebrooks have pointed out, ineffective, except in so far as it has helped to publicize the necessity for adequate fireguards. Health visitors are vigilant in this matter, and in describing causes of burns on the questionnaires some of them reported that guards were not used. But it is difficult to enforce the ruling on fire guards, when for instance, women have to use old-type kitchen ranges for cooking as well as space heating.

Even the most modern houses are not always designed to give the maximum protection to young children. Lack of space, insufficient shelving, and poor design of kitchens may result in infant injuries, while the increasing provision of domestic aids and labour-saving devices, particularly electrical equipment, mean even greater hazards for the inquisitive child. More adequate protection is required and more instruction should be given to mothers on the dangers which exist in every home.

\section{SUMMARY}

1. In the spring of 1948 the health visitors of 422 authorities in Britain obtained information from 4683 mothers on accidental injuries sustained by their young children during the first 2 years of life. This study formed part of a questionnaire inquiry into the health and development of these young children, who had all been born in one week, 3-9 March 1946.

2. The mothers seem to have remembered accurately the more serious accidents which received professional treatment during the 2 years under review. It is possible that some of the minor injuries which had not been treated were not recalled or entered on the questionnaires.

3. The rate for all serious injuries which received professional care was $79 \cdot 6$ per 1000 children in the sample. Treated cuts were almost as frequent as treated burns or scalds, each being sustained by about 37 per 1000 children. There were only 7.5 fractures per 1000 children. The sum of the rates for each type of injury $(81 \cdot 3$ per 1000) slightly exceeds the combined rate for all children injured (79.6 per 1000). This is due to the fact that in calculating the former rates eight children who were each involved in two serious accidents of different types were counted twice, i.e. once under each type of injury sustained.

4. In 1946-8 treatment of young children for burns or scalds and for serious cuts was most frequently given by general practitioners. Children under 2 years of age were admitted to accident wards of hospitals chiefly for the treatment of serious burns or scalds. Fractures were usually treated at out-patients' departments.

5. Although almost all accidents occurred at home, variations in housing conditions, as measured by crowding and the domestic facilities available, had little effect on the incidence of accidents among children under 2 years of age. Accidents happened most frequently when the children were beginning to walk and becoming inquisitive, and most injuries occurred either because they were not steady on their feet or because they had not developed 'heat-sense'.

6. Since domestic help was rare, most children had to play in the kitchen or 
living room while their mothers were doing the housework, cooking and laundry. In these circumstances, they were often exposed to the risk of injury.

I should like to thank the Chairman, Prof. James Young, and members of the Joint Committee for their advice, and in particular Prof. A. A. Moncrieff and Dr D. MacCarthy who made many constructive criticisms. Further, I owe a special debt of gratitude to Dr J. W. B. Douglas, the director of the inquiry, for his guidance and help, and to Mrs C. Mogford for her assistance with statistical calculations. I should also like to take this opportunity to thank on behalf of my Committee, the Medical Officers of Health and Health Visitors whose wholehearted co-operation made this survey possible, and the mothers in all parts of the country who willingly answered numerous and detailed questions on their children's health.

\section{REFERENCES}

Britten, R. H. \& Altman, I. (1941). Publ. Hlth Rep., Wash., 56, 609.

Britten, R. H., Klebba, J. \& Hailman, D. E. (1940). Publ. Hlth Rep., Wash., 55, 2061.

Brown, A., Lewis-Faning, E. \& Whitter, M. M. (1945). Brit. med. J. p. 144.

Colebrook, L. \& Colebrook, V. (1949). Lancet, $2,181$.

Donald, D. (1930). Lancet, $2,949$.

Douglas, J. W. B. \& Rowntree, G. (1949). Population Studies, 3, 205.

Dunbar, J. (1934). Glasg. med. J. 122, 239.

Gesell, A. \& Ilg, Frances (1943). Infant and Child in the Culture of Today, p. 132. New York: Harper.

Joint Committee of Royal College of Obstetricians and Gynaecologists and Population Investigation Committee (1948). Maternity in Great Britain. Oxford University Press.

Stocks, P. (1949). Sickness in the Population of England and Wales in 1944-1947. GeneralRegister Office.

Wilkinson, A. W. (1944). Brit. med. J. 1, 37.

(MS. received for publication 22. v. 50.) 